Regina Elena Crespo Gualda, coordenadora de Comunicação Social e Educação

\title{
Considerações sobre a educação ambiental e o papel do Estado
}

A lei que instituiu, no Brasil, a Política Nacional do Meio Ambiente se refere em vários pontos à necessidade de formação de uma consciência pública voltada ou dirigida para a preservação da qualidade ambiental. Reconhece, assim, a não-existência ou a existência em grau incipiente de uma consciência ecológica no país, ou, em outras palavras, de uma ideologia ambiental.

Sem dúvida, essa ideologia não existe, ou existe de forma difusa, no que reflete as próprias condições de desenvolvimento do país e da forma como ele se insere no sistema produtivo e cultural do mundo. Inusitado seria se essa consciência existisse, em grau de maturidade, quando o processo de industrialização e de urbanização no Brasil mal superou os seus primeiros estágios, ainda que esteja se desenvolvendo em ritmo acelerado.

Há dois modos de encarar a questão da formação da consciência: o primeiro, grosso modo, parte do princípio de que a consciência é algo derivado de si mesmo, um fenômeno intrinsecamente humano e inseparável dessa condição. O homem, em si, e separado de sua experiência e das condições particulares de existência dos seus vários grupamentos, já tem essa consciência, que lhe permite distinguir com absoluta clareza entre o bem e o mal, o que deve e o que não deve fazer, com absoluto domínio sobre os seus atos. É uma consciência, em síntese, que independe da experiência. Esta abordagem, contudo, é de pouca valia prática, dado o seu caráter ingênuo e maniqueista. Na medida em que a consciência, em seu máximo grau de desenvolvimento, já está presente em cada ser humano e em cada grupo, de uma vez por todas, nada restaria a fazer. Bastaria que os problemas individuais e sociais fossem deixados a cargo das sortes e azares do destino e tudo se resolveria com o máximo de eficácia. A segunda abordagem, antagônica a essa, é a de que a consciência é fruto da prática social, da experiência, das condições existenciais de cada indivíduo ou grupo social, de cada nação, não podendo posicionar-se em relação a determinado fato ou conjunto de fenômenos ou circunstâncias se esses fenômenos ou circunstâncias são estranhos, ou de emergência recente em seu meio. Esta forma de abordagem é mais adequada para o tratamento das questões sobre as quais trabaIhamos porque apresenta maior eficácia enquanto instrumento para a compreensão da realidade, dos fenômenos de que nos ocupamos e de como devemos nos organizar para controlá-los ou dirigi-los. Enfim, para desenvolver uma ação planejada, intencional.

É precisamente este o nosso caso. Só podemos iniciar um trabalho de formação de uma consciência pública (ou de ideologia) dirigida para a preservação da qualidade ambiental, só poderemos ordenar as nossas ações e avaliar a sua eficácia se partirmos do exame atento da nossa realidade, da história da nossa formação, que condicionou a produção dos resultados que são nosso presente. Sem saber de onde viemos, dificilmente (a não ser por alguma forma de revelação) saberemos o que somos e para onde ire, se formos, qual a validade de ter ido justamente nessa direção.

O Brasil é um país de formação rural e recente industrialização. A rigor, deveria ser dito que é um país em industrialização e esse caráter se revela pelo fato de que só muito recentemente a população 
urbana ultrapassou em número a população rural, assim como ainda mais recentemente a produção da riqueza nacional passou a ser obtida nos setores secundários e terciários da economia (indústria e serviços). Mesmo assim, o sistema industrial é distribuído muito desigualmente pelo território, sendo assim também irregularmente distribuída a população, verificando-se tanto vácuos populacionais (Amazônia) quanto áreas de grande densidade (Sudeste).

Além disso, tanto pela extensão quanto pela variedade, trata-se de um país riquíssimo do ponto de vista da dotação de recursos naturais. Ao contrário do que acontece em países de industrialização madura, de população densa e de recursos naturais em vias de exaustão - ou pelo menos de grandes limitações em vista da tecnologia em uso -, no Brasil prevalece a noção de inesgotabilidade dos bens ambientais. Ainda que a parte mais informada da população saiba que isso não é verdade, à vista do conhecimento que tem do processo de industrialização em outros países, esse é um valor que não pertence ainda ao grosso da população brasileira.

A introdução da tecnologia - e de tecnologia fundamentalmente orientada para o uso intensivo de recursos naturais - coloca também o perigo de um processo de degradação ambiental muito mais rápido do que ocorreu nos países de industrialização clássica. Isso devido ao fato de que esse processo de degradação não se efetiva somente no estágio da produção de bens, em si, mas também (como é o caso dos detergentes e dos defensivos agrícolas) no estágio do consumo ou aplicação a outros processos produtivos.

Não fora isso, tão somente a aglomeração da população em grandes centros urbanos já seria motivo para a emergência de processo rápido de degradação. Com efeito, no meio rural os resíduos descartados do processo de produção ou de consumo são reciclados pelo próprio meio. Ao contrário, no meio urbano, artificialmente simplificado e empobrecido do seu potencial auto-regenerador, a disposição ou a reciclagem dos resíduos do consumo e da produção se torna uma questão técnica e socialmente complexa.

A questão da preservàção e da melhorta da qualidade ambiental transcendem em muito o horizonte técníco e científico - ou o nível das soluções de engenharia - para tornar-se uma questão política, uma vez que exige não só o empenho dos indivíduos, mas também dos grupos sociais que, movidos por estruturas e padrões valorativos, produzem resultados através de suas atitudes, decisões, hábitos e comportamentos que não correspondem a vontades particulares de indivíduos particulares. Criar novos padrões valorativos que regulem as relações entre os indivíduos, a sociedade e o meio am- biente corresponde ao que chamamos de formação de uma consciência (ou ideologia) ambiental. Temos que conviver com a contradição de que, embora essas estruturas valorativas sejam valores sociais (culturais), o meio ambiente é afetado pelas ações e decisões de indivíduos concretos em situações concretas. E também com a constatação de que, em muitos momentos, essas situações concretas podem ser controladas por indivíduos concretos; em outras, não. Neste último caso, essas decisões e ações são obra de indivíduos particulares, mas condicionados pelos valores prevalecentes em grupos e classes sociais inteiros e em face de correntes de opinião que ultrapassem vontades individuais, por maior que seja a consciência que as move.

Seria ingênuo esperar que, em um país de urbanização e industrialização recentes, houvesse uma consciência pública - ou melhor, uma ideologia ou estruturas valorativas - madura em relação ao meio ambiente. É muito mais lícito partir do princípio que tal consciência não existe, ou é bastante incipiente, prevalecendo concretamente os padrões valorativos de uma sociedade rural, pré-industrial. Consciência essa que está embutida a presunção da inesgotabilidade dos recursos ambientais ou do seu usufruto extensivo e imediato, sem preocupações quanto à degradação ou à exaustão.

$\mathrm{Na}$ argumentação precedente quer-se deixar manifesto que a formação de uma consciência ambiental não resultará em um produto específico em um prazo determinado; ao contrário, é um processo, algo que um determinado momento pode ser avaliado tão somente quanto ao seu estado nesse momento e quanto à eficácia da estratégia que se utilizou para chegar a ele, posto que a realidade ambiental é dinâmica como tudo mais, mutável e cada vez mais ampla e rica é a idéia que se tem sobre ela. Além disso, por ser resultado da prática social, não há um instrumento suficiente para produzir por si só educação ambiental: o Estado é apenas um desses instrumentos. Eé legítimo que o Estado atue no sentido de acelerar o processo de formação de uma consciência ambiental, na medida em que, no seio de uma sociedade complexa, só este dispõe de uma informação global sobre o desenvolvimento da socieđade. Não será legítimo, porém, se estè ou aquele órgão do Estado reduzir a uma tarefa administrativa a produção de tal ideologia, sobrepondo-se aos mecanismos apropriados de geração de opinião a imprensa, o sistema educacional, os partidos políticos, etc.

A intervenção do Estado no processo de formação de uma consciência ambiental e de tratamento conseqüente das questões do meio ambiente pode se dar em vários níveis:

- através de: educação formal - mediante in- 
clusão dos temas ambientais como conteúdo obrigatório do currículo escolar, em todos os níveis de ensino, conforme está previsto na legislação que instituiu a Política Nacional do Meio Ambiente. De forma clássica, e do ponto de vista técnico, esses temas já estão incorporados a várias disciplinas (por exemplo, a biologia); resta, entretanto, acrescentarIhes os aspectos humanísticos, econômico e políti$\mathrm{co}$, pois estas são as novas faces dessas questões colocadas pela industrialização e o uso extensivo dos recursos naturais e do meio ambiente em geral;

- através da formação de quadros técnicos para a gestão dos recursos ambientais. Essa formação sempre se deu, de um modo ou de outro, no país, associada principalmente ao ramo das ciências naturais ou da engenharia. A par do caráter estritamente técnico, essa formação, refletindo um estado incipiente da consciência da sociedade sobre o meio ambiente, produziu-se sempre a partir de visões fragmentárias da realidade ambiental, carente, portanto, da visão integrada exigida pela nova realidade. Carece, pois, a sociedade brasileira do novo cientista e do novo técnico ambiental, em cuja estrutura intelectual se abrigue tanto o conhecimento dos aspectos estritamente técnicos, quanto dos aspectos culturais e políticos que essa questão envolve. Cabe, assim, especificar com a profundidade possível o perfil cognitivo desse novo profissional e colocar a demanda pela sua formação junto ao sistema educacional e de pesquisa do país;

- educação de massa - esta é uma via que bem pode ser explorada por um trabalho dirigido não para a criação imediata de valores abstratos, mas pa- ra a reorientação de hábitos de indivíduos concretos (ou comunidades restritas) em suas aç̃es concretas e passíveis do seu controle. A modificação de hábitos e a prática reiterada de hábitos modificados, estimulados pela aquisição de informação, constituem modos eficazes de geração de valores que novamente se transformam em ações a um nível cada vez mais elevado de consciência.

Em conclusão, pode-se dizer que educação ambiental não se constitui em um tipo especial de educação, mas faz parte do processo geral, de formação política, na medida em que as relações dos indivíduos com o meio ambiente (tanto no que se relaciona com a sua transformação, quanto no que diz respeito à sua defesa) se configura como expressão concreta da consciência social. Não são relações puramente econômicas ou afetivas - são relações políticas genuínas, uma vez que essas relações entre um homem e a natureza não se esgotam em si, mas refletem e afetam as relações dos homens uns com os outros. Assim, a consciência ecológica terá a sua formação propiciada tanto pela introdução dos temas ambientais nos currículos escolares, em todos os níveis, quanto pela sua inserção na discussão do partido político, do sindicato, da associação de classe, enfim, em todos os setores de atividade da sociedade civil. Por esse motivo, a educação ambiental carece de sentido se for isolada da participação política, sob pena de esvaziar-se sob a forma de uma consciência ingênua ambiental e idílica, ou na idealização de uma natureza simplesmente decorativa, um adorno de vidas privilegiadas e não uma fonte de possibilidades de usufruto e bem-estar para todos. 


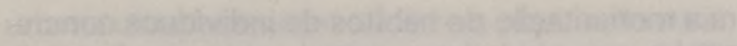

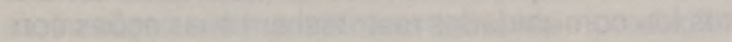

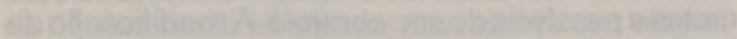

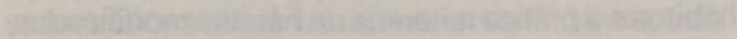

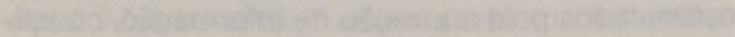
warrothe

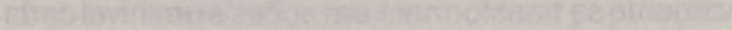

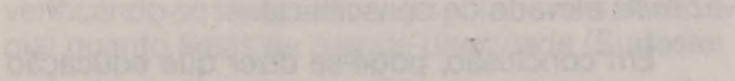

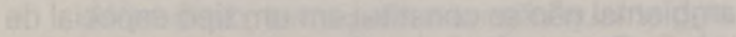

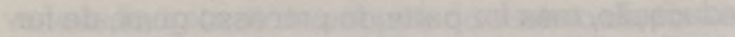

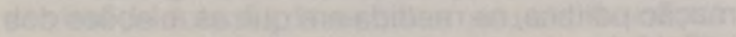

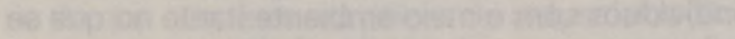

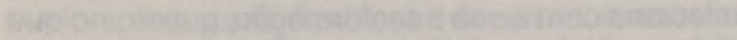

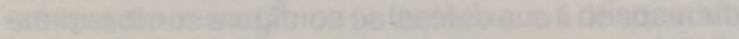

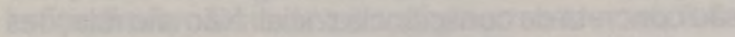

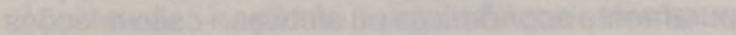

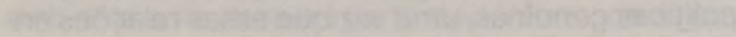

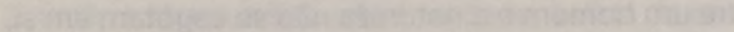

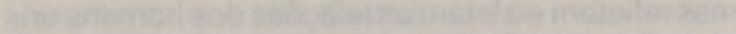
36at:

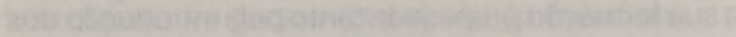
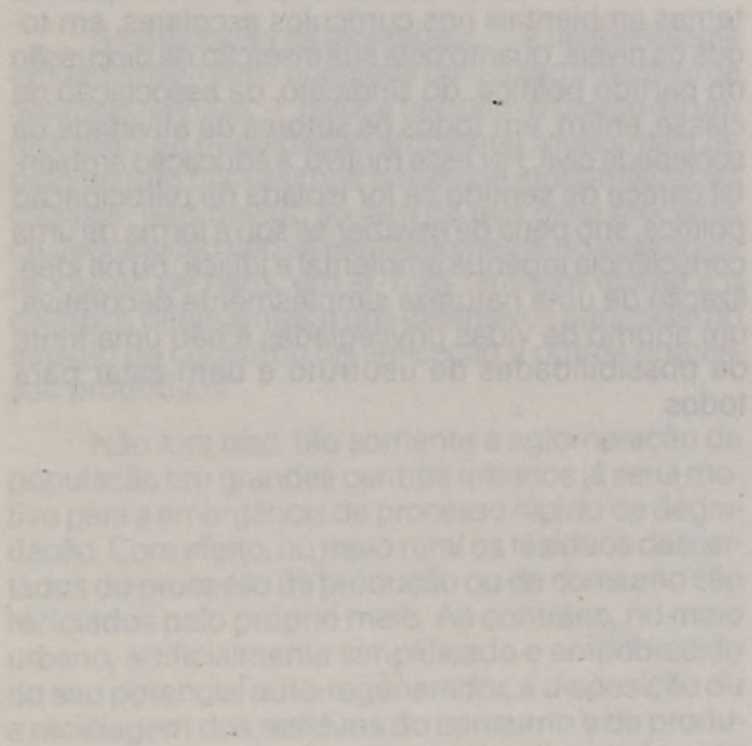

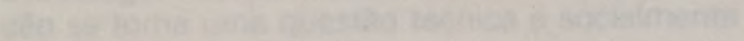

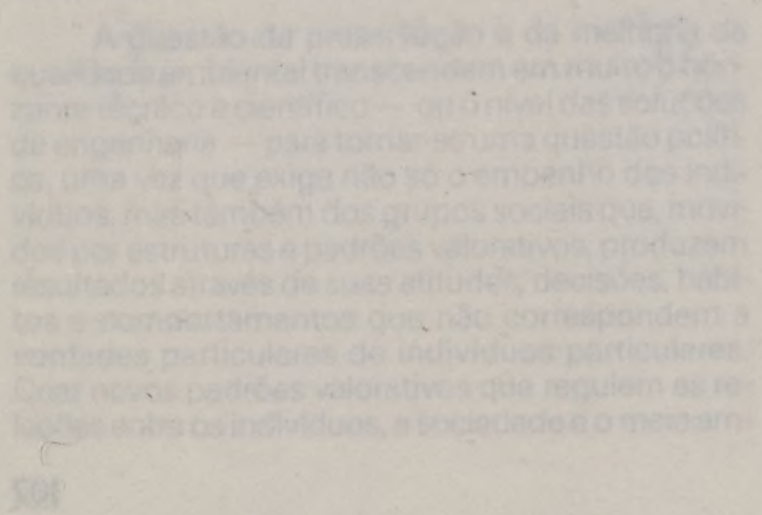

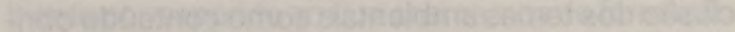

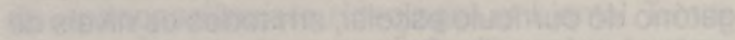

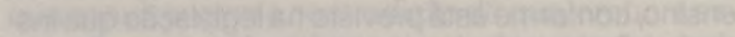

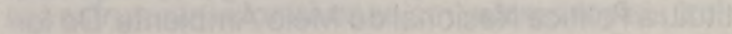

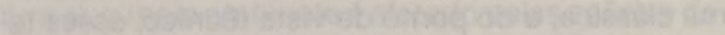

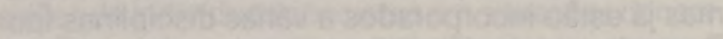

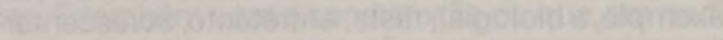

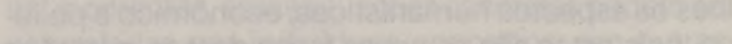

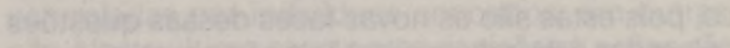

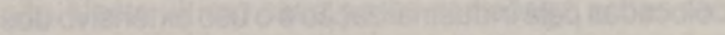

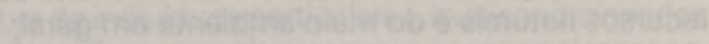

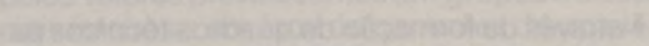

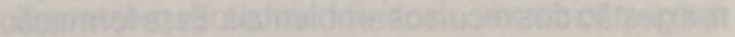

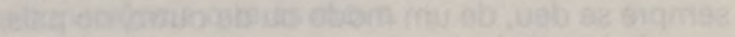

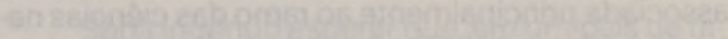
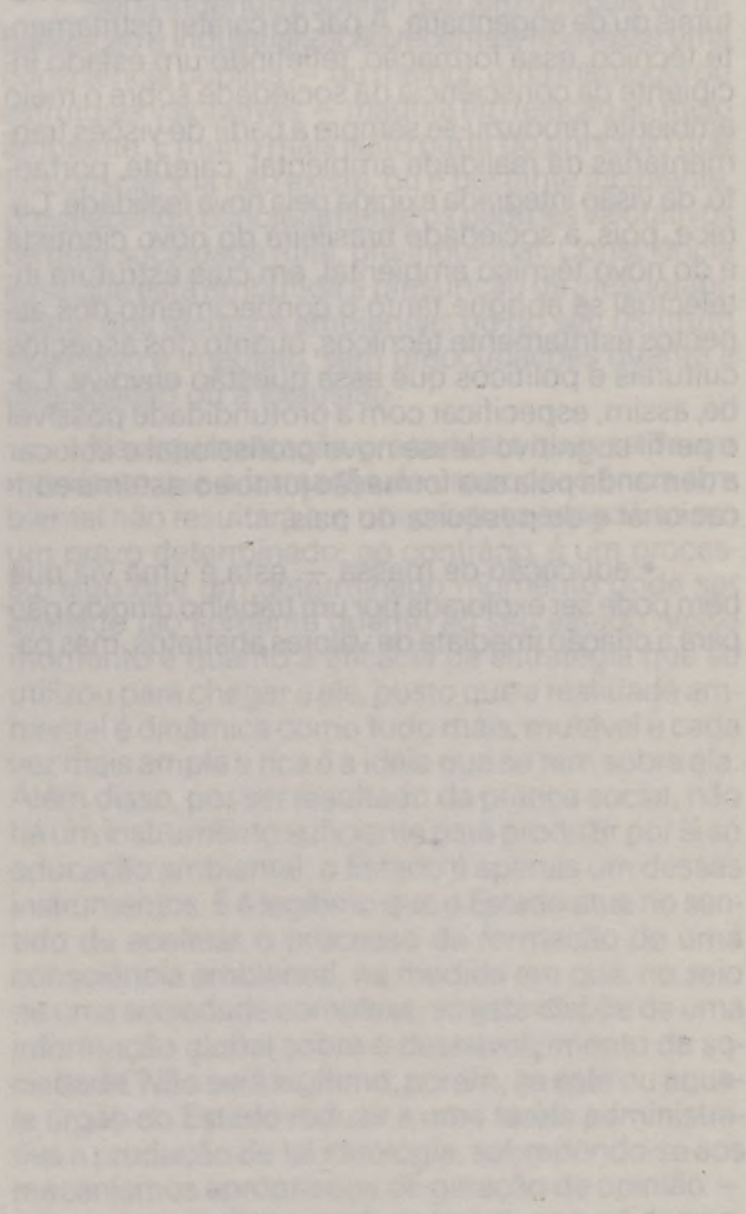

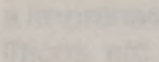
a 